\title{
Cyberbullying: Resources for Intervention and Prevention
}

\author{
Charles E. Notar*, Sharon Padgett, Jessica Roden \\ Secondary Education Department, Jacksonville State University, 700 Pelham Road N \\ Ramona Wood Building A-3, Jacksonville, AL 36265-1923, United States of America \\ *Corresponding Author: cnotar@jsu.edu
}

Copyright (C) 2013 Horizon Research Publishing All rights reserved.

\begin{abstract}
Cyberbullying is of major concern in the educational field. Unlike normal bullying cyberbullying is anonymous and can take place anywhere which is a major problems for schools. Topics covered in the article are types of cyberbullying and can happen anywhere. What resources are available today to combat cybullying. The article reviewed all article from 2005-2013 that related to cyberbullying resources. Roles in cyberbullying, school climate, prevention and intervention programs, law and resources available are topics covered in the article. There is a myriad prevention and intervention program. More research is needed due to the various school systems approach to cyberbullying prevention and intervention.
\end{abstract}

Keywords Cyberbullying, Prevention And Intervention Programs, Cyber Aggression, School Climate

\section{Negative Aspects of cyberbullying}

Relationship problems, victims experience powerfully negative effects (especially on their social well-being); and the reactive behavior, both from schools and from students, was generally inappropriate and ineffective [1]. A Patchin and Hinduja [2] study found students who experienced cyberbullying, both as a victim and an offender, had significantly lower self-esteem than those who had little or no experience with cyberbullying. Cyberbullying impacts students'wellbeing, schooling, and and peer relationships of many young people [3].

The negative impacts of bullying on schooling, relationships and the emotional and psycho- logical health of young people who are its victims can be long term; in some cases, the impacts continue into early adulthood [4]. There are also long-term implications for bullies; for example, they have been found to typically exhibit higher levels of antisocial, violent and/or criminal behavior in adulthood [4, 5]. These impacts, both for the bully victim and the bully, create ongoing social and economic costs for the community. As the penetration and use of communication technologies grows, especially among young people, it is necessary to consider the potential for cyberbullying to increase the frequency and severity of victimisation [3]. By all accounts, cyberbullying is an increasingly serious public mental health problem with sometime devastating consequences $[6,7]$.

Cyberbullying has an effect on both teachers and those being cyberbullied. Qualitative evidence gathered through a survey of teachers has demonstrated that cyberbullying affects the working lives of staff and impacts severely on staff motivation, job satisfaction and teaching practice. Cyberbullying victims face various academic and social problems. They range from withdrawal from school activities, school absence, and school failure, to eating disorders, substance abuse, depression, and even suicide [e.g., 8, 9] At the very least, cyberbullying undermines the freedom of youth to use and explore online resources [10].

National Crime Prevention Council's [11] website identified four important themes that can help schools better understand the nature of the cyberbullying phenomenon and what they might do to support students has been identified by various studies. First, the high percentage of students being affected by cyberbullying and the content of the messages suggest cyberspace can be a graphic, scary, threatening, and generally pretty unsettling virtual world with few laws or norms for socially acceptable behavior. Typical teen tensions around relationship issues, including break-ups' envy, intolerance, and ganging up, are playing out in a far more dangerous environment. Students, who often lack the moral compass or leadership skills to govern themselves, are increasingly interacting with peers in this unsupervised setting. Adults, who normally would be supervising the lives of teens, are left on the outside - without the technological expertise or understanding of the environment to be of much help. The study suggests that cyberspace operates like the Wild West once did where anything goes. People take the law into their own hands and retaliate because there is no governance structure to protect them from further victimization. Until schools, courts, parents, and internet/technology providers join forces to establish and enforce behavioral standards in cyber-space, students' lives are being negatively affected by a very uncivilized virtual world that is spilling over into their real lives.

Second, cyberbullying is causing students to experience feelings of anger, powerlessness, fear, and sadness. In other words, cyberbullying has some of the same negative 
outcomes for targets as face-to-face bullying, which studies have shown leads to (among other things) sadness and depression, powerlessness, fear, and delinquency [12], or more aggressive/retaliatory behavior/ The added dilemma is that cyberbullying is easier because of the anonymity of the attack. It is more pervasive with high numbers of students participating, by-standing, and/or being targeted. Cyber targets can feel helpless because they do not know what to do to make it stop [1].

Third, it is clear that students are not equipped to handle cyberbullying.They generally do not seek help because of fear of reprisal, embarrassment, or because they assume adults will not act. Some try to avoid the situation which may stop a particular incident but does little to protect them long-term or discourage the cyberbully. Some become very withdrawn which can affect their school work, their friendships, and ultimately lead them to dangerous, self-destructive behavior. For those students who do take action, they often wait until the bullying reaches intolerable levels and then retaliate, which is inappropriate and potentially very dangerous. Indeed, the data show a pattern that bullying begets bullying, reflecting the kind of cycles we see in other social systems, which are insidious in their reinforcement of the problem and extremely difficult to interrupt[1].

Adolescence is a particularly important time for identity development. During this period, a youth's social environment and social interactions with peers largely influence the identity formation process. Thus, adolescents seek behaviors, situations, and social environments that help value themselves positively and avoid those that affect them negatively. Overall, this affects a child's perceptions and acceptance of his or her changing self, and it plays a "critical role in directing his or her personal and even professional growth trajectory." The Journal of Adolescent Health recently released a study that examined the association between depression and frequency of involvement in cyberbullying. It concluded that experience with cyberbullying has a more negative effect on adolescent development than traditional bullying, and victims may suffer long term sociological and psychological consequences. Although cyberbullying does not involve personal contact between an offender and a victim, it can cause serious psychological harm, including depression, low self-esteem, anxiety, alienation, suicidal intentions, concentration and behavioral problems, and even physical harm, such as stress-induced headaches and nausea. Some victims even bring bullying-induced psychological, mental, and sociological issues into adulthood. Researchers consistently report higher rates of depression and poor self-esteem in adults who experienced bullying as an adolescent [13].

\section{Avenues of cyberbullying aggression}

Table 1 provides a noninclucsive list of ways and means of cyberbullying.

There are many different avenues of cyberbullying aggression to perform a wide range of negative Internet and mobile phone practices. The following are not all inclusive definitions of the forms and represent the most commonly used forms:

Cyberharassment. Harassment through the Internet that involves an adult. An adult can harass a child, a child can harass an adult, and an adult can harass another adult [14]. Repeatedly sending nasty, mean, and insulting messages [15].

Table 1. Ways and Means of Cyberbullying

\begin{tabular}{|c|c|c|}
\hline Blogs & Instant messaging (IM) & Profile sites \\
\hline Burnbooks & iPod & Social media/Networking \\
\hline media/Networking & & Sexting \\
\hline Cameras & iphotos & Texting \\
\hline Cell phones & Internet & Video clips \\
\hline Chat rooms & Land line phone & Videoconferencing \\
\hline Cyberbullying & Message boards & Virtual worlds \\
\hline Cyberstalking & On-line chat (OOVOO) & Webblogs \\
\hline Email & Personal digital assistant (PDA) & Wiki \\
\hline Gaming devices & Personal pictures of others & Youtube \\
\hline Happy-slapping & Photoshopping & Podcast \\
\hline Inappropriate pictures & . & \\
\hline
\end{tabular}


Cyberbullying or harassment by proxy. (1) When cyberbuilies get someone else (or several people) to do their dirty work; or (2) When a bully intentionally provokes a victim to lash back to get the victim in trouble. If this happens to you, don't lash back. Contact your Internet service provider, talk to an adult, or talk to your friends about it. [14]. Harassment occurs when a student, or several students, says mean and hurtful things or makes fun of another student or calls him or her mean and hurtful names completely ignores or excludes him or her from their group of friends or leaves him or her out of things on purpose, tells lies or spreads false rumors about him or her, sends mean notes and tries to make other students dislike him or her, and other hurtful things like that. When we talk about harassment, these things happen repeatedly, and it is difficult for the student being harassed to defend himself or herself. We also call it harassment, when a student is teased repeatedly in a mean and hurtful way. But we do not call it harassment when the teasing is done in a friendly and playful way. Also, it is not harassment when two students of about equal strength or power argue or fight [16].

Cyberstalking: Sending abusive messages repeatedly through the Internet or by using a mobile phone. The messages are often threatening in nature, and instill fear that the stalking might move offline and into the target's real life, even becoming physically threatening $[15,17]$.

Denigration: "Dissing" someone online. Sending or posting gossip or rumors about a person to damage his or her reputation or friendships ([15].

Exclusion/Gossip Groups: Singling out and/or excluding an individual from a group. An online equivalent of relational bullying, the group then taunts the excluded person using the Internet or a mobile phone $[15,17,18]$.

Falsify Identity: This occurs when the offender hacks another's account and begins posting content or pictures aimed at causing embarrassment or reputation damage to the victim, often resulting in isolating the victim from others. [18].

Flaming: Corresponding through chat rooms, e-mail, and instant messenger via electronic communication. Flaming refers to arguments or messages that are supplemented with graphics, specific images, and harsh language to drive home a point. Examples include photo and video postings and sexting $[14,15,17,19]$. To prevent flaming, do not respond, save the messages so you can show a trusted adult, and don't worry if the message is from someone you don't know or recognize; there are ways to track the person down. [14].

Masquerading/Impersonation: Sophisticated forms of cyberbullying in which an individual creates a false identity and harasses another while pretending to be someone else. Masquerading or impersonation can include theft of another person's login information to broadcast harassing or humiliating information about the target online [17]. Pretending to be someone else and sending or posting material to get that person in trouble or danger or to damage that person's reputation or friendships [15].

Online Grooming: When a predator builds an online relationship with a child by giving compliments or a "shoulder to lean on" or sending gifts until the child trusts the predator. Typical 'grooming" lines include a) Where is the computer in the house? b) Are your parents around much? c) You can always talk to me. d) I'm always here for you. e) You don't deserve how they treat you f) You have a great personality. g) You're beautiful. You should be a model. To protect yourself from a groomer, (1) always know whom you are talking to online, (2) don't give out personal information, (3) don't post seductive or inappropriate pictures of yourself or others online, (4) never meet up in person with anyone you meet online, and (5) talk with your parents if you feel suspicious about something online. 14].

Outing: An individual disclosing private information online to friends that is then disseminated over the Web through social Web sites and/or mobile phones. That person is "outed," with devastating effects. It is often these situations that have lead to the teen suicides of late, as these targets do not know how to regain control of their lives after such broad public humiliation $[15,17]$.

Phishing. An attempt to get your personal information by pretending to be a site you are familiar with or trust. Always be sure you know where your e-mails come from. Don't give information over the Internet to sites that don't look valid [14].

Sexting: Sexting is sending sexually explicit messages via cell phone or instant messenger. As technology has advanced and cell phones have the capability to record and send photos and video, the practice of sending suggestive and explicit pictures has increased especially among teens [15].

Trickery: Talking someone into revealing secrets or embarrassing information or images online [15].

\section{Roles within Cyberbullying}

The anonymity of cyberbullying fosters a sense of a lack of inhibition and of invincibility because the bully can remain faceless [20]. Individuals who might otherwise be afraid to engage in bullying behavior (e.g., victims wishing to retaliate against stronger individuals who have bullied them, individuals reticent to engage in face-to-face bullying) are more willing to do so [7].

Children exposed to cyberbullying, whether as a cyberbully, cybervictim, or both (bully/victim), spent more time on computer based social activities. Nearly two thirds of cyberbully/victims were also traditional bully/victims. While preliminary, results suggest that efforts to prevent cyberbullying may need to focus on patterns of Internet use, amount and type of social activities, and exposure to traditional bullying as risk factors for engaging in cyberbullying [21].

Some routine types of Internet activities increase the odds of victimization. Participation in social networking sites was found to represent a risk for being bullied online. Having an online profile on these sites apparently provides information on both personal characteristics and contact 
information and exposes the adolescent to potential contact with motivated offenders, probably unknown to the teen [22].

The private information is the raw material that might be used by potential offenders to call them by names, threaten them, and make fun of them. It is not surprising that participation in chat rooms increases the risk of cyberbullying, as participants are likely to engage in conversations with strangers, some of whom may be sexual offenders [22].

Cyberbullying is a growing concern as the usage of the internet as growing among youth. One step towards identifying cyberbullying in online forums is the identification of features in forum posts which may be related to cyberbullying [23].

\section{School Climate}

Bullying, and being bullied, has a long history in schools [15]. Cyberbullying is a form of psychological cruelty. Although cyberbullying usually occurs off school grounds, schools are experiencing its repercussions [Li, 2006 as cited in 20]. Any program to attack cyberbullying starts with school climate. Without the full support of all people that have a role in a prevention program there will not be a program that provides the safety everyone should have. School climate sets the stage for everything else in bully prevention. Adults are the corner stone in establishing a school climate. Two complementary aspects of school climate--structure and support--are important for adolescents' safety in school according to [24].

Bullying and cyberbullying are events that are not occurring with less frequency as time passes. The results of a study by Sbarbaro and Smith [25] parallel data from previous studies showing the prevalence of bullying in the middle school years. The results from this study indicate a need to further identify influential factors revolved around bullying and cyberbullying. The current instruments, as well as others that may exist, should continue to be tested to see if there is meaningful data to apply and use within other summer programs in California, or other states, similar to the Summer Connection Program. In addition, future research on relationships among the variables within this study will enhance understanding of the risks associated with bullying and cyberbullying. Additional research should also continue examining gender and ethnicity differences related to bullying and cyberbullying, and how bullying occurs through electronic means via Web postings, e-mails, chat rooms and text messaging (cyberbullying). This may also show a continued increase in electronic usage (text messaging, cell phone usage) among youth [25].

The middle school climate was viewed by some respondents as one that tolerates bullying. Teachers were not always aware of the bullying that occurred or committed to efforts to react to what was seen. Disciplinary and educational efforts aimed at responding and reducing the bullying was seen as ineffective by several of the participants [26].

While structure and support are important they are the framework and details of how they will be seen by everyone. In this respect, relationship between classroom management and bullying in the classroom are vital to preventing bullying. [27]. School environment, classroom management, teacher practices, and student behavior are factors of school climate [27]. Classroom teachers may benefit from viewing bullying as a behavior management issue in the educational setting [28]. Acknowledge that cyberbullying is real. To confront cyberbullying it is essential to develop a safe, respectful school climate. Research in the last 30 years has identified the benefits of a positive school climate, including its role in preventing traditional bullying [Ma, 2001 as cited in 29].

How bullying is understood by members of the school community is important because differences in definitions could result in an inconsistent approach and affect the success of intervention work. Research evidence suggests that pupils and teachers may have different interpretations of what constitutes bullying [30].

The findings suggest that young adolescents differ in their ability to participate in the construction of social order depending on the school/home context. Further, bullying is mainly framed as an issue of the school climate on the part of the participants. The student-teacher relationship (as a hidden curriculum), academic competition and pressure of academic achievement contribute significantly to the bullying discourse in students talk [30].

Various authorities advocate research designed to investigate attributes of both the bully and the victim (e.g., age, gender, ethnicity, social status, economic circumstance). That knowledge should contribute to the development of more empirically-based interventions [31].

\section{Schools' Roles in Preventing Cyberbullying}

In order for students to attain and retain good health and reach their potential for academic success, it is imperative that school districts address the issue of bullying at all grade levels if each student is to adopt a healthy lifestyle in relation to behaviors that contribute to unintentional injuries, intentional injuries, and social problems. When analyzing the grade level and bullying risk factors, the results of this study support previous findings indicating grade level plays an important role. Ninth graders were bullied more than seventh and eighth graders. Significant relationships indicated that as the grade level increased so did being bullied in the hallway, being threatened by other students in the hallway, being ignored, having a bully steal or damage something that belonged to another student, and seeing others being shoved [25].

Due to the negative impact of cyberbullying on students, schools must take action to reduce incidents both inside and outside of school. This becomes a particularly sensitive issue 
when eyberbullying takes place outside of school, yet it impacts students across all settings. School administrators must proceed with caution, however, when disciplining students for speech that occurs outside of the classroom, examining whether first amendment rights are protected [32]. Because of potential legal issues, it is in both the schools' and the students' best interests to carefully draft and implement preemptive policies and prevention programs aimed at reducing, if not eliminating, cyberbullying [33]. What happens at home on computers and cell phones cannot be helped at school; however, preventative measures should be put in place to illustrate to children that bullying is bad and can cause long term harm to their peers.

The review of literature suggests there is a lapse in preventative intervention to create and maintain awareness and safety for young people. Implications and guidelines are provided for school personnel to address this problem and develop prevention strategies. [Reprinted by permission of the publisher] [20]. Schools are the best line of defense against the growing problem of cyberbullying and offers a guide for schools wary of First Amendment lawsuits by students punished for their cyberspeech. In many cases, a student engaging in cyberbullying of a classmate will create a substantial disruption at school or interfere with the right of the victim to an environment conducive to learning, thus justifying action by the school under the Tinker standard. Other Supreme Court cases regarding indecent or offensive speech and speech the Court viewed as promoting drug use may provide helpful arguments for schools accused of overstepping constitutional boundaries. This also suggests that schools may wish to argue that courts should show more deference to disciplinary decisions made by schools that have punished students for cyberspeech directed at another student as opposed to cyberspeech about a school official. Courts could make this distinction based on an analogy to defamation law [34].

One issue affecting how schools respond to cyberbullying is many administrators have no experience with this type of bullying; therefore, they cannot relate; or they are inept at maneuvering the various technology platforms in which it exists. For camp leaders, too, there is a limited window of direct involvement with staff or camper families. Trying to monitor or manage the relationships kids maintain with each other outside of camp is laden with obstacles making this a tough problem throughout the year [35].

In a study by Stauffer, Heath, Coyne, and Ferring [33] the first research question investigated teachers' general attitudes regarding the impact of cyberbullying on students. In general, participants indicated cyberbullying does not "toughen kids up;' has long-lasting negative effects on students, and does not "prepare students for life." Although the majority of teachers' attitudes and perceptions reflect what we would hope to see among teachers, up to one fourth of teachers did not endorse socially desirable responses. These teachers were either neutral or they strongly agreed with perceptions that countered desired attitudes. For example, $18 \%$ of participants indicated they were neutral to or agreed with the statement, "Cyberbullying toughens kids up." About 25\% of participants reported they were neutral to or disagreed with the statement, "Cyberbullying has long-lasting negative effects." The same percentage indicated they were either neutral to or agreed with the statement that cyberbullying "prepares students for life" (see Figure 3 above). .

Stewart and Fritsch [36] found cyberbullying to have the potential to significantly disrupt the educational environment, and it also can result in severe psychological and physical consequences for victims. Welker [37] concluded cyberbullying disruption during the school day adds to the complexity of maintaining school operations, safety, and academic achievement. With the advancement of technology, there is a gap in the literature on the disruption in schools, particularly on the schools' culture, from cyberbullying. [38] stated teachers and administrators overestimated the reported prevalence of student perpetrators and victims of cyberbullying.

\section{School Intervention and Prevention Strategies}

The strategies for prevention of cyberbullying start with a definition of bullying. Only then can a school develop school intervention and prevention share a district's policies and consequences for bullying with staff, develop a map of locations where bullying is most likely to occur, advise staff to remain vigilant for evidence of cyberbullying, distribute a list of indicators that may suggest victimization, provide support groups for students new to the school setting, remind staff that bullying may be in the form of gay bashing, advise victims to respond appropriately, encourage bystanders to be friends to the victim, and post a code of conduct in all classrooms [39])

Schools should intervene to prevent cyberbullying off-campus and should define cyberbullying in school regulations. Poland [40] proposes that teachers and parents be educated about cyberbullying and that educators limit the use of cellular phones by students in school settings.

The advent of social networking has highlighted cyberbullying. Library media specialists can be an advocate in fighting cyberbullying. They can work with teachers to instruct students about cyberbullying and how to combat it [41].

If you believe that you are a victim of cyberbullying the one thing you must do_is not erase the offending material from the system. Print a copy of the material and immediately report the incident to a school official (principal, assistant principal, school counselor, teacher, or director of technology). All reports of harassment in cyberspace will be investigated fully. Sanctions may include, but are not limited to, the loss of computer privileges, detention, suspension, separation, or expulsion from school [42].

5.2 Some other prevention and intervention strategies are indicated by various authorities. They are:

Kowalski et al. [43] defined nine intervention tips for 
responding to cyberbullying:

- Save the evidence: Print copies of messages and Web sites.

- For a first offense, if minor in nature, ignore, delete, or block the sender.

- Reporting: If a face or offensive profile targeting your child is set up on a social networking site, report it to the site host.

- Investigate: Monitor your child's online presence.

- Communicate: If the perpetrator is another student, share evidence with the school personnel.

- Parental involvement: If the perpetrator is known and cyberbullying is continuing, contact the child's parents and share your evidence.

- Legal advice: If the parent of the perpetrator is unresponsive and the behavior continues, contact an attorney or seek legal advice.

- Law enforcement: Report the cyberbullying to the police.

- Mental health support: If your child expresses emotional distress or thoughts of self-harm seek help from a school counselor or other mental health professional immediately [44].

\subsection{Prevention Summary}

Various authorities advocate research designed to investigate attributes of both the bully and the victim (e.g., age, gender, ethnicity, social status, economic circumstance). That knowledge should contribute to the development of more empirically-based interventions [31].

In conclusion at a minimum schools need to take the following steps in formulating their cyberbullying prevention program: a) Define cyberbullying; b) Have strong policies in place (Everyone will know what they are enforcing and it is very important because of law suits. c.) Train staff, students and parents on policy and be able to identify cyberbullying when they see it and d) Employ internet filtering technology to insure enforcement. However, Stauffer, Heath, Coyne, and Ferrin [33] provide a prevention caveate stating bully prevention programs produce minimal change in student behavior.

\section{Law}

Ideally, new cyberbullying legislation will guide school districts on what actions they can and must take, as well as under what circumstances, says Justin Patchin, who along with Hinduja coauthored Bullying Beyond the Schoolyard [Corwin, 2008, as cited 45]. A point needs to be made that states and local jurisdictions have laws on the books regarding cyberbullying. Some of the states that are addressing cyberbullying also allow discipline for off-campus cyberbullying offenses. These states include: Georgia, Nebraska, New Jersey, South Dakota, Arkansas, Connecticut, Louisiana, Massachusetts, New Hampshire.
Every state but Montana has anti-bullying laws, but more and more states are expanding or updating their laws to address cyberbullying specifically.

In addition to state and local laws the Federal Communications Commission (FCC) mandates policies. School boards have to create or update current internet use policies to include wording they are teaching internet safety by July 1, 2012. Schools are also encouraged to provide education and training not only on the appropriate use of these sites but on their potential for enhancing the learning experience. The FCC also specifically points to sites such as Facebook and YouTube and confirms these sites are potentially harmful to minors but not harmful in and of themselves.

Before you do anything regarding cyberbullying prevention check with the school lawyer. First amendment rights are a great concern. Since almost all states have laws against bullying on the books, some cases of cyberbullying that involved the deaths of students have resulted in costly lawsuits against schools and school districts.

Cyberbullying occurs off campus using home computers or other devices and a nonschool Internet connection. In these situations, school administrators are often reluctant to get involved. Although this is muddy legal water and courts typically support students' rights to freedom of expression, courts have upheld the actions of administrators who disciplined students for off-campus action (Ma, 2001 as cited in 29]. Most cases that go to trial are about First Amendment rights and failure to intervene in students' victimization. In either case a school district can be liable to hundreds of thousands of dollars.

In these cases, to legally justify intervening, school officials must show that a student's misbehavior substantially or materially disrupted learning, interfered with the educational mission or school discipline, or threatened other students. Basically, educators must show that they had to stop day-to-day school activities to address the behavior that occurred off-site or to respond to school-based consequences of that behavior [for example a spike in students using cellphones during class as many of them gossip about a malicious incident that happened on Facebook] [Ma, 2001 as cited in 29].

The adoption of these new laws, with specific language addressing cyberbullying and electronic harassment may make schools and districts more vulnerable to lawsuits when they fail to initiate the policies and protections required to keep students from being victimized. By including off-campus discipline, states are attempting to mitigate the risks associated with the ubiquitous 'presence of social media in students' lives.

The authors, upon review of numerous articles on cyberbullying, concluded a school system must have a lawyer involved when dealing with cyberbullying. This lawyer needs to be conversant in the First Amendment that will be used against a school system in court. The lawyer should be involved in the writing of the school policy as well as its defense. The courts will ask for the schools bullying 
program. In addition to the plan it will ask for documentation that parents, faculty, staff, and administration have been provided information on dissemination of the program to include how it will have referral of students and consequences.

\section{Resources}

There are a plethora of programs available that should be explored, if for no other reason, to get ideas that fit your situation. The ten areas below are not all inclusive.

\subsection{Public School Sponsored Programs}

The Seattle Public School District took a proactive stance last year when it launched a pilot curriculum to prevent cyberbullying in junior high and middle schools.

Mike Donlin (as cited in 46] senior program consultant who led the curriculum's development, says the district created its own resources rather than use off-the-shelf products, ensuring that the resources would be easy to use and integrate into existing curricula. "There also was the issue of cost," he said. "We believed we could create something great with far less expense."

Unlike many programs that address cyberbullying piecemeal -- focusing only on Internet safety skills, for example -- the Seattle curriculum attacked the entire problem by using the four most promising prevention practices:

- Debunking misperceptions about digital behavior,

- Building empathy and understanding,

- Teaching online safety skills, and

- Equipping young people with strategies to reject digital abuse in their lives.

The Seattle curriculum also recognizes the importance of parental engagement by offering take-home letters and activities. Academically, the curriculum focuses on writing, which boosts student skills in a tested area, while allowing the program to discard common, ineffective practices. Instead of asking students to sign a pre-crafted pledge, for example, the curriculum prompts them to write personal contracts for themselves about their online behavior.

The curriculum also educates teachers about cyberbullying and introduces language they can share with students. "We couch lessons in a way that resonates for teachers, too," said Donlin. "So, we use the Golden Rule. We use the old-fashioned mantra 'don't kiss and tell' to address sexting."

Still, some information requires repeated explanation. Some might wonder, for example, why the curriculum prompts students to try to see things from the bully's perspective. A student can be a victim, a bystander, and a bully in different moments, Donlin (as cited in 46] explained. A child is bullied at school this morning, and when the child gets home he/she can go on online and bullies back. The child has moved from victim in to a bully. Technology gives them tremendous There is freedom and power to reach out and touch in nearly every moment, for good or evil using the various technologies available.

Learning to resist the urge to "bully back" is important, as is un-learning some common myths about being online. Kids often think they can be anonymous, or that what they do on the Internet is fleeting. Both ideas are mistaken. The Library of Congress, for example, is archiving' all Twitter messages sent from March 2006 forward. Even the "mean tweets" will be immortalized for future generations. "Everything students do online reflects on them, permanently," says Donlin.

For teachers, a common stumbling block revolves around First Amendment protections and discomfort about corralling students' speech. Donlin [as cited in 46] believes that should not be a problem. "We have Second Amendment rights to possess weapons, but that doesn't mean we allow children to bring guns to school," he observed. "When it comes to cyberbullying, we're still talking about school safety."

Therefore, schools should incorporate lessons on cyberbullying into life skills and bullying prevention classes, as well as implement effective social skills and conflict resolution education $[4,29,32,47,48,49$, Olweus, 1993 as cited in 25].

The Anti-Defamation League has developed workshops for educators, school administrators, and parents: "Trickery, Trolling, and Threats: Understanding and Addressing Cyberbullying" [50] and "Youth and Cyberbullying: What Families Don't Know Will Hurt Them" (Anti-Defamation League, [50]. They have also developed online lesson plans for elementary (called "Building a Foundation for Safe and Kind Online Communication"; Anti-Defamation League, [50], middle (Dealing with the Social Pressures that Promote Online Cruelty; Anti-Defamation League, [50] and secondary students (Cyberbullying and Online Cruelty: Challenging Social Norms; Anti-Defamation League, [50].

The Anti-Defamation League, ConnectSafely, Facebook, Myspace, Wired Safety, and others are working collaboratively to craft a comprehensive website, on-air programming, and a digital responsibility curriculum [45].

Social networking sites such as Facebook and MySpace allow the creator of the site to post information in multimedia formats about herself or himself. Other users designated as Friends by the creator of the site are allowed to make postings on the site. The site is available only for viewing and reading by anyone else on the Internet.

\subsection{Curriculum Based Programs}

Several curriculum based programs that purport to address cyberbullying in schools have been developed. Examples include the iSAFE Internet Safety Program, Cyber Bullying: A Prevention Curriculum [43], Sticks and Stones: Cyberbullying [51], and Lets Fight It Together: What We All Can Do to Prevent Cyberbullying [52]. Typically, these programs involve video or webisodes related to cyberbullying and a series of scripted lessons to help students discuss issues related to cyberbullying and efforts to 
prevent and how to address cyberbullying when it occurs. Each of these programs has the potential to be used as a stand alone intervention to help prevent cyberbullying or they can be embedded within a larger schoolwide antibullying program. Because there is a strong overlap between victims and perpetrators of traditional bullying and cyberbullying $[7$, 53], a comprehensive prevention and intervention program may be a preferred approach. The Bullying Prevention Program (Olweus, Limber, \& Mihalic, 1999, as cited in 20] has been recognized as a national model and a Blueprint Violence Prevention [54].

The Second Step Violence Prevention Program has been efficacious in reducing aggressive behaviors and increasing prosocial behaviors $[55,56,57]$ found programs that have been identified as important in helping bullies learn both to think before they act and to change their behaviors.

A Common Sense Media, along with groups such as BrainPop, Learning.tom, Media Awareness Network, and Web Wise Kids, all offer a breadth of resources to address these issues. While these organizations strongly encourage administrators to institute the full range of digital literacy curricula, the combination of students with smartphones, the expanded usage of social networking sites, and high-profile media coverage of recent cyberbullying tragedies has elevated the issue of cyberbullying to the top of many administrators' worry lists.

\subsection{On-line Programs}

www.stopcyberbullying.org. This Web site by the group WiredSafety includes information on identifying cyberbullying, preventing it, and how to handle it if it happens to you.

http://www.stopbullying.gov/

www.stopbullying.gov. This government Web site has a ton of information on both bullying and cyberbullying.http://www.athinline.org/

www.athinline.org. Get facts on digital abuse and cyberbullying and learn how to deal with those things and help others at this Web site from MTV.

Bully Block app. Block unwanted text messages, pictures, and calls with this app for Android phones. You can also record to a secret file and send the information to your parents. [40].

Netiquette, a set of rules for Internet etiquette, may be an important means of reducing disinhibited behavior online [58].

The iSafe Internet Safety Program (i-SAFE Inc, 1998, 2009) is a subscription-based prevention curriculum for students in Grades K-12. School personnel, parents and/or community leaders are provided a professional development

program either in person or via DVD

Nersmarta (Http://www.metsmartz.org)

CyberSmart

(hyyp://www.cybersnartcurriculum.org/home)

MTV initiative "A Thin Line" (www.athinline.org), aims to end digital abuse, the network enlisted psychologists, cybercrime experts, and youth activists [45].

Many of the computer profile sites (e.g., MySpace) allow the user to report abuse by simply accessing a link at the bottom of each profile. Facebook has an e-mail address (abuse@facebook.com) available to report any misuse of their site. Last, students should tell a trusted adult (parent, teacher, or older sibling) about the incident. For that reason, both in the school and in the home there should be a climate in which students feel comfortable reporting and talking about incidences of bullying [54].

\subsection{Parent Programs}

A free filtering program will let parents track both questionable e-mails and cellphone text messages.

MouseMail, e-rnail for improper words and unknown contacts and forwards dubious messages to a parent's account.

Parents (or students themselves) can use one or more of the popular search engines such as Google to check and see if any personal information has found its way onto the Web.

Parents can go to a search engine (e.g., Google) and type in the full name within quotation marks - such as "John Snakenborg." All references (as well as others with the same ss and/or instant message screen name and newsgroup postings by clicking on "groups" above the search screen on Google. If there is unwanted information, parents can ask Google or other search engine sites to disable the information. If a youngster's information is posted online and he or she is younger than 13 years of age, parents should notify the Web site or the online service that they must remove the information because it violates the Children's Online Privacy Protection Act. If they do not respond, parents can contact the Federal Trade Commission directly at http://www.ftc.gov/ [59].

Teaching parents about Internet safety and helping them establish rules for Internet use is another way to play an active role in the prevention of cyberbullying. On their website, Common Sense Media offers "Parent Tips," helping parents establish a code of conduct for technology use [60].

Parents download an app to a child's smartphone and set up the program so that they are forwarded questionable text messages [61].

\subsection{Tips for Helping Parents Prevent Cyberbullying [17].}

Given the extensive exposure kids have online, are there ways to prevent and protect them from online cyberbuilying and abuse? There are a number of steps that can be taken to prevent and protect kids from cyberbullying.

1. Talk to your children about respecting others and explain that cyberbullying

Hurts: Explain the rules for interacting with people in real life also apply for interacting online or through cell phones. Ask kids if the things they say online would still be okay if said offline. Would they think twice about asking the some questions, showing the some pictures? If they start a rumor 
about someone/ something, chances are something will be started about them. Is that okay?

Teach them to consider these feelings as a barometer when engaging in more online activity.

2. Explain to your children the consequences if they misuse the technology (e.g., damaging their reputation, getting in trouble at school or with the police):

Photos can be tampered with and defaced. Help kids understand the meaning of 'forever,' because postings on the Internet are forever.

3. Demonstrate appropriate Internet use: Your children learn from your behavior

and imitate it. Don't harass or joke about others while online, especially around your children. Decide rules for your own family time: Don't text at the dinner table or let your kids use their cell phones during that time either.

4. Become involved in your children's cyberspace: Sit at the computer and let them teach you how they use the internet and what they are doing. The goal is to be able to monitor their online activities without them feeling watched. If your children feel intimidated, they may go to the extremes to hide their online activity. Ask them if they have ever been harassed or ridiculed and encourage them to tell you if this happens.

5. Restrict cell phone use and access: You can work with your carrier to restrict use to certain times of day and to restrict the number of texts. You can also restrict the ability to send or receive pictures and access to the Internet.

6. Set time limits on Internet use: Limit the number of hours per day and the times during the day when your children are allowed to surf. More often than not, cyberbullying occurs late at night.

7. Use an 'Internet Use Contract' and a 'Mobile Phone Use Contract' to create clear and understandable rules about what is acceptable and what is not: Make sure you and your children sign the contract and agree to the terms. Place the contracts in a visible place, such as near the computer. Do this when you first bring in technology, so the rules are set from the beginning. If you haven't already given them a contract, and kids abuse their privilege to use technology appropriately, contracts can still be instituted.

8. Place the computer in a family room or somewhere visible - or work out a plan with them that lets them know that technology is a privilege that comes with responsibility: You, as the parent, must have access to their technology. Explain to kids that while you won't need to check on them unless given a reason, they need to uphold appropriate behavior online or there will be consequences, such as loss of the technology and increased supervision.

9 Encourage your child to notice cyberbullying incidents and report incidents they come across: Make them feel safe so they report to you.

10. Use filtering and blocking software: Many software programs are now available that allow a range of possible solutions at low cost.

11. Teach kids how to protect themselves: Kids can make good choices if counseled on how to do so. They don't have to respond online; they can disengage; they can secure their content with appropriate privacy settings; and they can save harassing messages to share with teachers, counselors, parents, etc. Teach your children that they can talk to adults and get help. They don't have to be alone.

12. Documentation of all correspondence and your efforts to manage a problematic situation is your best protection from a future problem: Retain all records of Internet use between campers. This prevents denials by creating objective evidence of situations that arise.

13. Role Model Appropriate Behavior: Make examples of those staff members who maintain positive, respectful interactions offline and online all year long.

14. Parent Partnerships: Working with parents is needed to help defuse cyberbullying situations that discussion of appropriate online behavior. Do not desist on their own. Encourage quick reporting, and encourage parental discussion of appropriate online behavior.

\subsection{Monitoring Programs}

Services such as AT\&T FamilyMap, Verizon Family Locator, and Sprint Family Locator let parents keep track of the physical whereabouts of their children by tracking the location of the kids' mobile phone (you can find links to all three of these services at find.pcworld.com/71755). The services do provide some peace of mind, but they also have some limitations

Cell phone monitoring can be done either physically or with the help of a software service like Mobile-Spy or WebWatcher Mobile.

Many software programs allow a parent or school district to filter and block content based on key words, Web site addresses, and specified categories. For example, Net-Box Blue has developed Cyber Bullying Prevention Engine and PureSight has Child-Friendly Internet. Both programs block, quarantine, and report offensive e-mails, instant messages, and other communiques on the basis of keywords or sources identified by the user. Most of these commercial software programs provide a third party (e.g., parent or school administrator) the ability to monitor a summary of violations (e.g., messages delivered with targeted keywords) allowing the identification of potential cyberbullying without the need to review each and every electronic communication. Although most online bullying originates from the home computer [20] youth can access the Internet from many other locations (e.g., the public library, a friend's home, electronic devices [7]; thus, these software programs provide only limited victim protection [54].

Stop, Save, Block, and Tell. The first thing students should be taught is to refrain from responding in any manner to the cyberbully. Students should save the e-mail, text message, picture, and so forth, that constitutes the basis of the cyberbullying as this will help identify and possibly prosecute the cyberbully and block any further communication from this individual using the blocking 
options available through your Internet or cell phone provider. "Stop, Block, Tell" technique emphasizes the need to stop before responding impulsively in a negative way, suggests blocking the cyberbully to prevent further communication, and telling an adult about the incident. Students need to understand the importance of reporting incidences of cyberbullying so others do not become victims. [60].

\subsection{Applications}

iPhone and iPad app "Over the Line," which acts like a "digital morality meter" to help teens understand the difference between digital use and abuse by asking them to rate real-life stories about sexting, sextortion, textual harassment, digital dating abuse, and other forms of online hostility [45].

A school system in Blount County in North Carolina uses TipSoft for Education software to collect incident reports from students. Engines. The software was adopted by the Blount The software enables students to use text messaging, web forms, or the mobile application TipSubmit to offer information cyber-bullying, potential violence and dangerous situations. The school has been seeing a drop in illegal activity [65].

The Safe2Tell hotline is a Colorado system for students, teachers and parents to anonymously report violent or troubling events. The goal is to break the "code of silence" and intervene before an event occurs. The number is 1-877-542-SAFE. The website is safe2tell.org [67].

McAfee ${ }^{\circledR}$ Safe Eyes ${ }^{\circledR}$ Mobile App, is a filtered browser that helps parents manage children's Internet use on the Apple iPhone, iPad and iTouch, has earned top honors in the Mom's Choice Awards for family-friendly products [68].

A free filtering program called MouseMail from Consumer Electronics Show in Las Vegas, filters e-mail for improper words and unknown contacts and forwards dubious messages to a parent's account. Parents can send them on to their child or not. MouseMail's free Web-based e-mail is available at MouseMail.com. The free text app message filtering applications for most major smartphones, with Apple iPhone [69\}.

\subsection{Miscellaneous Programs}

The following prgrams are not all inclusive but deal with a specific aspect of cyberbullying. In examining the Lions-Quest Conflict Management program, it addresses areas such as bullying, prejudice, and classroom conflicts [62].

Sticks and Stones: Cyberbullying involves a film that depicts a student who is the victim of cyberbullying. The film is accompanied by a comprehensive teacher's guide to help facilitate group discussion and ways to extend the learning. This program was developed for use in high school programs.

"Let's Fight It Together: What We All Can Do to Prevent
Cyberbullying" is a curriculum with video segments designed to be delivered in an assembly or classroom setting and followed up by suggested activities intended for students between 11 and 14 years.

Classroom interventions are designed to improve an individual classroom's social climate [63]. The goal of student education should be to empower adolescents to independently prevent and address concerns of cyberbullying and Internet safety [32, 56, 64].

Kowalski, Limber, and Agatston (2008). Cyber bullying: Bullying in the digital age. Malden Blackwell Publishing.

Cyber Bullying: Bullying in the Digital Age provides essential information on the nature and prevalence of this epidemic. Cyber bullying: Bullying in the digital age [66].

Hathcote and Hogan [65] provide general information on cyberbullying, electronic resources for parents and victims and educators dealing with cyberbullying and books on legal perspective on cyberbullying.

Picture books provide a thoughtful, provocative way to engage students in conversation and can be used to bring together disparate groups to talk about the same topic [66].

Kopple [66] provides 35 prevention book abstracts for k-12 sorted by grade levels.

Bully prevention programs produce minimal change in student behavior [67].

In that cyberbullying usually occurs when adults are not present, parents must play a more active role in monitoring their son's or daughter's online usage. Most current cyberbullying programs are based on practical beliefs about prevention and logical approaches rather than on scientific evidence. Researchers and practitioners must work together to identify scientifically based prevention and intervention programs designed to address both traditional bullying and cyberbullying [68].

\subsection{Summary of Resources}

Cyberbullying also allows perpetrators to victimize a greater number of targets in front of a larger audience without significant risk [69]. Accordingly, most cyberbullies do not fear any punishment for their participation in this hands-off activity [54].

These are just a few examples of the kind of ongoing programs that could involve students, parents, teachers, and administrators working together to create new norms for acceptable techno-behavior. They represent just one prong of a three-prong approach. However, because in reality, teaching students about internet safety only addresses the symptom of the problem. Underlying cyberbullying is the much larger issue that students often lack the ability to handle social tensions, particularly those that center on relationship issues. So while technology training is important, it is not sufficient to bring about real change. To get to the core of the problem, schools should add a second prong to their approach by greatly expanding the ways they are helping students deal with the social tensions they face on a daily basis. Parents and educators may be focusing so much 
on making students feel good about themselves that they fail to see (or do not want to see) the tensions and dark side of contemporary teen life. Ignoring this reality results in young people who are not equipped with the necessary skills to handle peer interaction and rejection. Possible remedies include a more systematic role for school counselors and teachers in helping students learn to navigate relationships, beginning in elementary school. Teachers and administrators need more training about their role in recognizing and responding to student social tensions - including the need for vigilance in maintaining school climates that do not tolerate peer cruelty of any kind [1].

\section{Conclusion}

There are a large quantity of resources that have been developed and have experience behind them. However, no program meets all the requirements needed to cyberbullying. Any program must be tailored to change the school climate and address the cyberbullying avenues of aggression, the roles within cyberbullying, and the law.

\section{REFERENCES}

[1] Hoff, D. L., \& Mitchell, S. N. (2009). Journal of Educational Administration, 47(5), 652-665.

[2] Patchin, J. W., \& Hinduja, S. (2010). Cyberbullying and self-esteem. Journal of School Health, 80(12), 614-624.

[3] Price, M., \& Dalgleish, J. (2010). Cyberbullying experiences, impacts and coping strategies as described by Australian young people. Youth Studies Australia, 29(2), 51-59.

[4] Patchin, J. W., \& Hinduja, S. (2012). Cyberbullying prevention and response: Expert perspectives. Routledge, Taylor \& Francis Group. (ED529048)

[5] Kulig, J. C., Hall, B. L., \& Kalischuk, R. G. (2008). Bullying perspectives among rural youth: a mixed methods approach. Rural \& Remote Health, 8(2), 11p.

[6] Srabstein, J. C., Berkman, B. E, \& Pyntikova E; (2008). Antibullying legislation: a public health perspective. Journal of Adolescent Health, 42 (1), 11-20.

[7] Ybarra, M. L., \& Mitchell, K. J. (2004). Online aggressor/targets, aggressors, and targets: a comparison of associated youth characteristics. Journal of Child Psychology \& Psychiatry, 45(7), 1308-1316. DOI: 10.1111/j.1469-7610.2004.00328.x.

[8] Chibbaro, J. S. (2007). School counselors and the cyberbully: interventions and implications. Professional School Counseling, 11(1), 65-68. DOI: 10.5330/PSC.n.2010-11.65

[9] Klomek, A., Brunstein; S. A., \& Gould, M.. S. (2011). Bullying and Suicide: Detection and Intervention. Part of a special report: Suicide: Part 2. Psychiatric Times, 28(2), 27-31.
[10] Hinduja, S., \& Patchin, J. W. (2009). Bullying beyond the schoolyard. Thousand Oaks, CA: Corwin.

[11] National Crime Prevention Council's http://www.ncpc.org/topics

[12] Aluedse, O. (2006). Bullying in schools: A form of child abuse in schools. Educational Research Quarterly, 30(1), 37-49.

[13] Albin, K. A. (2012). Bullies in a wired world: The impact of cyberspace victimization on adolescent mental health and the need for cyberbullying legislation in Ohio. Journal of Law \& Health, 25(1), 153-188.

[14] Musracchi, J. (2009). R U Safe? Educational Leadership, 66(6), 78-82.

[15] Siegle, D. (2010). Cyberbullying and Sexting: Technology Abuses of the 21 st Century. Gifted Child Today, 33(2), 14-65.

[16] 16] Tokunaga, R. S. (2010). Following you home from school: A critical review and synthesis of research on cyberbullying victimization. Computers in Human Behavior, 26 (3), 277-287. DOI: 10.1016/j.chb.2009.11.014.

[17] Haber, J. D., \& Daley, L. A. (2011). Cyberbullying Protection Plan. Camping Magazine, 84(2), 32-37.

[18] Witmer, D., \& Katzman, S. (1997). On-Line Smiles: Does Gender Make a Difference in the Use of Graphic Accents? Journal of Computer-Mediated Communication, 2(4).

[19] Mason, K. L (2008). Cyberbullying: A preliminary assessment for school personnel. Psychology in the Schools, 45(4), 323-348.

[20] Twyman, K., Saylor, C., Taylor, L. A, \& Comeaux, C. (2010). Comparing children and adolescents engaged in cyberbullying to matched peers. CyberPsychology, Behavior \& Social Networking, 13(2), 195-199. DOI: 10.1089/cyber.2009.0137.

[21] Mesch, Gustavo S. (2009). Parental Mediation, Online Activities, and Cyberbullying. CyberPsychology \& Behavior, 12(4), 387-393.

[22] Moore, M. J., Nakano, T., Enomoto, A., \& Suda, T. (2012). Anonymity and roles associated with aggressive posts in an online forum. Computers in Human Behavior, 28 (3), 861-867.

[23] Gregory, A., Cornell, D., Fan, X., Sheras, P., Shih, T., \& Huang, F. (2010). Authoritative school discipline: High school practices associated with lower bullying and victimization. Journal of Educational Psychology, 102(2), 483-496.

[24] Sbarbaro, V., Smith, T. M. (2011). An exploratory study of bullying and cyberbullying behaviors among economically disadvantaged middle school students. American Journal of Health Studies 2011, 26(3), 139.

[25] Dranoff, R. (2008). Teacher and student perceptions of bullying and victimization in a middle school. Dissertation Abstracts International Section A: Humanities and Social Sciences, Vol 68(7-A), pp. 2826. [Dissertation]

[26] Allen, K. P. (2012). Off the radar and ubiquitous: Text messaging and its relationship to 'drama' and cyberbullying 
in an affluent, academically rigorous US high school.

[27] Journal of Youth Studies, 15(1), 99-117.

[28] Crothers, L. M., \& Kolbert, J. B. (2008). Tackling a problematic behavior management issue: teachers' intervention in childhoodbullyingproblems. Intervention in School and Clinic, 43(3), 132-139. DOI: $10.1177 / 1053451207311606$

[29] Hinduja, S., \& Patchin, J. W. (2011). Educational Leadership, 68(5), 48-52.

[30] Maunder, R. E., Harrop, A., \& Tattersall, A. J. (010). Pupil and staff perceptions of bullying in secondary schools: comparing behavioural definitions and their perceived seriousness. Educational Research, 52(3), 263-282. DOI: $10.1080 / 00131881.2010 .504062$

[31] Bibou-Nakou, I., Tsiantis, J., \& Assimopoulos, H. (2012). School factors related to bullying: A qualitative study of early adolescent students. Social Psychology of Education: An International Journal, 15(2), 125-145.

[32] Wong-Lo, M. (2009). Cyberbullying: Responses of Adolescents and Parents toward Digital Aggression. ProQuest LLC, Ph.D. Dissertation, University of North Texas, 99 pp.

[33] Willard, N. (2011). School response to cyberbullying and sexting: The legal challenge. Brigham Young University Education \& Law Journal, 1, 75-125.

[34] Stauffer, S., Heath, M. A., \& Coyne, S. M., \& Ferrin, S. (2012). High school teachers' perceptions of cyberbullying prevention and intervention strategies. Psychology in the Schools, 49(4), 352-367.

[35] Lane, D. K (2011).Taking the lead on cyberbullying: Why schools can and should protect students online. Iowa Law Review, 96(5), 1791-1811.

[36] Haber, J. D., Daley, L. (2011). Camping Magazine, 84(2), 32-37.

[37] Stewart, D. M., \& Fritsch, E. J. (2011). School and law enforcement efforts to combat cyberbullying. Preventing School Failure, 55(2), 79-87. DOI: 10.1080/1045988X.2011.539440.

[38] Welker, H. S. (2010). Principal perspectives on social networking and the disruptive effects of cyberbullying. ProQuest LLC, Ph.D. Dissertation, Walden University. 2010 155 pp. (ED523370)

[39] Brunner, J., \& Lewis, D. (2007). Ten strategies to address bullying. Principal Leadership: High School Edition, 7(9), 73-75.

[40] Poland, S. (2010). LGBT Students Need Support at School. District Administration, 46(1), 44-44.

[41] [41]Frederick, K. (2009). Times Educational Supplement, 10/30/2009, Issue 4863, 30-30.

[42] Anderson, N. B. (2011). Cyberbullying among school aged children: Implications for prevention and intervention programs. Dissertation Abstracts International: Section B: The Sciences and Engineering, 71(9-B), 2011. pp. 5776.

[43] Kowalski, R. M., \& Limber, S. P., \& Agatson, P. W.
(2012).WCyberbullying: Bullying in the digital age. (2nd ed.). Riley-Blackwell, $282 \mathrm{pp}$.

[44] Wong-Lo, M., \& Bullock, L. M. (2011). Digital Aggression: Cyberworld Meets School Bullies. Part of a special issue: Cyberbullying By: Preventing School Failure, 55(2), 64-70. DOI: 10.1080/1045988X.2011.539429

[45] Whelan, D. L. (2011).The bully in the backpack. School Library Journal, 57(10), 29-36.

[46] Holladay, J. (2011). Cyberbullying. Education Digest, 76(5), 4-9.

[47] Rubin-Vaughan, A., Pepler, D., Brown, S., \& Craig, W. (2011). Quest for the golden rule: An effective social skills promotion and bullying prevention program. Computers \& Education, 56(1), 166-175. DOI: 10.1016/j.compedu.2010.08.009.

[48] Walker, H. M., Stiller, B., \& Golly, A. (1999). First step to success: A collaborative home-school intervention for preventing antisocial behavior at the point of school entry. In: Young exceptional children: Practical ideas for addressing challenging behaviors. Sandall, S. (Ed.), Ostrosky, M. (Ed.). Denver, CO, US: Division for Early Childhood of the Council for Exceptional Children, 41-48. [Chapter]

[49] Anti-Defamation League. www.adl.org/education/cyberbullying/

(2013).

[50] [51]Bullock, L. M., Wong-Lo, M., \& Gable, R. A. (2011). Cyberbullying: What Is It and How Can We Combat It? Preventing School Failure, 55(2), 63.

[51] Wilson, E. (2007). As bullies go high-tech, lawmakers say schools should be fighting back Seattle Times, The (WA). 02/07/2007.

[52] Juvonen, J., \& Gross, E. F. (2008). Extending the school grounds?--Bullying experiences in cyberspace. Journal of School Health, 78(9), 496-505.

[53] Snakenborg, J., Van Acker, R., \& Gable, R. A. (2011). Cyberbullying: Prevention and intervention to protect our children and youth. Preventing School Failure, 55(2), 88-95.

[54] Frey, K. S., Hirschstein, M. K., Edstrom, L. V., \& Snell, J. L. (2009). Observed reductions in school bullying, nonbullying aggression, and destructive bystander behavior: A longitudinal evaluation. Journal of Educational Psychology, 101(2), 466-481. DOI: 10.1037/a0013839.

[55] Craig, W. M., Pepler, D., \& Atlas, R. (2000). Observations of bullying in the playground and in the classroom. School Psychology International, 21(1), 22-36.

[56] Rigby, K., \& Smith, P. (2011). Is school bullying really on the rise?

[57] Social Psychology of Education, 14(4), 441-455

[58] Shea, S.E. (1994). Guide for parents. What to do about bullying... Contemporary Pediatrics, 13(2), 115-116.

[59] Bradley, T. (2011). What are your kids doing online? PC World, 29(6), 33-34.

[60] Diamanduros, T., \& Downs, E. (2011). Creating a safe school environment: How to prevent cyberbullying at your school. Library Media Connection, 30(2), 36-38. 
[61] Snider, M. (01/05/2011). MouseMail traps kid's cyberbullies. USA Today.

[62] Kim S, \& Laird M. (1993) An outcome evaluation of Lions Quest'Skills for growing' Grades K-5, Available at: http://www.Lions-quest.org.

[63] Olweus, D. (2012). Cyberbullying: An overrated phenomenon? European Journal of Developmental Psychology, 9(5), 520-538.

[64] Aftab, P. (2010). Online safety for students. FDCH Congressional Testimony. 06/24/2010. Commitee Name: House Education and Labor Accession

[65] District Administration. (2013). Tennessee school system cuts down on illegal activity with texting program.District
Administration, 49 (1), 3-3.

[66] Kowalski, R. M., Limber, S. P., \& Agatston, P. W. (2008). Malden: Blackwell Publishing,. xv, 218 pp.

[67] McGraw, C. (2013).Parents, experts offer tips to curtail cyberbullying Gazette, The (Colorado Springs, CO), $02 / 10 / 2013$

[68] McAfee. (2011). Safe Eyes Mobile App for Safe Web Browsing. (2011). Business Wire (English). 11/30/2011.

[69] Snider, M. (2011).MouseMail traps kids' cyberbullies. USA Today, 01/05/2011. 